\title{
Somatosensory evoked potentials in amyotrophic lateral sclerosis
}

\author{
VITTORIO COSI, ${ }^{*}$ MARCO POLONI, $\dagger$ LETIZIA MAZZINI, ${ }^{*}$ ROBERTO CALLIECO \\ From the Clinica Neurologica, University of Pavia, ${ }^{*}$ and the Clinica Neurologica I, University of Milan, $\dagger$ Italy
}

SUMMARY Forty five patients with amyotrophic lateral sclerosis were investigated, by means of somatosensory evoked potentials, in order to detect the presence of subclinical sensory changes. Cervical SEPs from the median nerve and cortical SEPs from the median and tibial nerve were recorded, showing a delay of $\mathrm{N} \overline{13}$ and subsequent components; the latency of the first constant cortical potential was also increased in many patients. Only the SEPs from the tibial nerve showed a decrease of amplitude. These results suggest a pathological slowing of conduction along the central sensory pathways in amyotrophic lateral sclerosis.

Amyotrophic lateral sclerosis is generally considered to be a system disease because of selective involvement of upper and lower motor neurons. Sensory disturbances characteristically are absent in typical amyotrophic lateral sclerosis, although cramps and paraesthesias may occur; nevertheless a certain number of detailed pathological studies have claimed to show the presence of changes in sensory nerve myelinated fibres, ${ }^{2}$ in spinocerebellar pathways, ${ }^{3}$ Clarke's nucleus, ${ }^{4}$ posterior columns ${ }^{5-7}$ and thalamus. ${ }^{8}$ These changes have been reported more frequently in familial than in sporadic amyotrophic lateral sclerosis. ${ }^{9}$ A patient with a chronic pain syndrome associated with amyotrophic lateral sclerosis has recently been described. ${ }^{10}$ In a series of investigations about the possible involvement of subsystems other than motor neurons in sporadic amyotrophic lateral sclerosis, we have examined somatosensory evoked potentials (SEPs) in 45 patients in an attempt to detect the presence of subclinical alterations.

\section{Materials and methods}

Forty five patients with amyotrophic lateral sclerosis (34 males and 11 females) of mean age $=51.7$ years (range

Address for reprint requests: Prof. V Cosi, Clinica Neurologica Università, 27100 Pavia, Italy.

Received 27 September 1983 and in revised form 6 December 1983.

Accepted 16 December 1983

A brief communication on this subject was held at the $\mathrm{V}$ International Congress on Neuromuscular Diseases, 12-18 September 1982, Marseille
22-67) were investigated. The diagnosis of amyotrophic lateral sclerosis was made by at least two different neurologists on the ground of usual clinical and investigation features, after a follow-up period ranging from six to 14 months. There were no familial cases.

The clinical picture of these patients were divided into: typical amyotrophic lateral sclerosis without bulbar signs, typical amyotrophic lateral sclerosis with bulbar signs, bulbar and pseudobulbar amyotrophic lateral sclerosis and amyotrophic lateral sclerosis with predominant lower motor neuron involvement (without pyramidal signs). The patients were further divided into three groups, according to the duration of the disease: $I=$ up to 12 months, II = from 13 to 24 months, III = more than 24 months. The muscular impairment was classified as light, moderate or heavy, according to the clinical evaluation of the functional capacity. The tallness of the patients and the presence or the absence of cervical spondylosis on plain radiographs was also considered. These clinical features are shown in table 1 .

The control cases, matched for age, sex and tallness were sampled from normal subjects of the laboratory. The patients, relaxed in an arm-chair, in a silent room, were requested to close their eyes. The stimulating electrodes were placed on the skin overlying the median nerve at the wrist and the tibial posterior nerve at the ankle; both sides were sometimes examined. The stimulus had a duration of $0.1 \mathrm{~ms}$, a frequency of $3 \mathrm{~Hz}$ and an intensity of $20 \%$ above that required to induce a modest muscular twitch. The recording silver-silver chloride electrodes were placed at C3 or at C4-Fpz (cortical SEPs after stimulation of the median nerve), at $\mathrm{Cz}-\mathrm{Fpz}$ (cortical SEPs after stimulation of the tibial nerve), according to the 10-20 International System and above 7 th cervical spine (C7-Fpz) for cervical SEPs after stimulation of the median nerve. Electrode impedance was low, less than $3 \mathrm{kohm}$. Signals were amplified and averaged by a Neuroaverager OTEBiomedica 1239-512 words (bandpass 1.6-1000 Hz, bin- 
Table 1 Clinical data in 45 patients with amyotrophic lateral sclerosis

\begin{tabular}{llllll}
\hline Clinical forms & $\begin{array}{l}\text { Number of } \\
\text { cases }\end{array}$ & Mean age (yr) & Duration of the disease & $\begin{array}{l}\text { Number of } \\
\text { cases }\end{array}$ & Mean age (yr) \\
\hline $\begin{array}{l}\text { Typical amyotrophic lateral sclerosis } \\
\text { without bulbar signs }\end{array}$ & 16 & 48.9 & Group I ( \$ 12 months) & 12 & 49.7 \\
$\begin{array}{l}\text { Typical amyotrophic lateral sclerosis } \\
\text { with bulbar signs }\end{array}$ & 12 & 51.5 & Group II (12-24 months) & 16 & 49.9 \\
$\begin{array}{l}\text { Bulbar involvement alone } \\
\text { Lower motor neuron involvement }\end{array}$ & 25 & 60.5 & Group III (> 24 months) & 17 & 52.1 \\
Total & 45 & 56.8 & 51.7 & & \\
\hline
\end{tabular}

\begin{tabular}{|c|c|c|c|c|c|}
\hline Muscular impairment & $\begin{array}{l}\text { Number of } \\
\text { cases }\end{array}$ & $\begin{array}{l}\text { Mean duration of } \\
\text { disease }\end{array}$ & Cervical spondylosis & $\begin{array}{l}\text { Number of } \\
\text { cases }\end{array}$ & Mean age \\
\hline \multirow{2}{*}{$\begin{array}{l}\text { Light } \\
\text { Moderate } \\
\text { Heavy }\end{array}$} & \multirow{2}{*}{$\begin{array}{r}14 \\
20 \\
9\end{array}$} & \multirow{2}{*}{$\begin{array}{l}18.6 \text { months } \\
23.6 \text { months } \\
19.6 \text { months }\end{array}$} & Present & 32 & $54 \cdot 5$ \\
\hline & & & Absent & 13 & $44 \cdot 6$ \\
\hline
\end{tabular}

width $0.195 \mathrm{~ms}$, averaging of $256-512$ responses for the cortical SEPs; bandpass 16-3000 Hz, binwidth $0.039 \mathrm{~ms}$, averaging of 512-1024 responses for the cervical SEPs). The peaks were visually identified; the latencies were measured by a marker on the oscilloscope and checked after transcription by means of an $x-y$ plotter; the amplitudes were measured peak to peak. For the cervical SEPs recorded after stimulation of the median nerve the following parameters have been considered: $N \overline{9}, N \overline{1}, N \overline{13}$ latencies and $\mathbf{N} \overline{9}-\mathbf{N} \overline{11}, \mathbf{N} \overline{11}-\mathbf{N} \overline{13}, \mathbf{N} \overline{9}-\mathbf{N} \overline{13}$ intervals. For the cortical SEP recorded after stimulation of the median nerve we have identified and measured the latencies and the amplitudes of the first six peaks from $P \overline{15}$ (it was seldom absent due to the frontal reference): $N \overline{19}, P \overline{26}, N \overline{34}$, $\mathrm{P} \overline{44}$, N $\overline{63}$. For this investigation were considered specifically the $N \overline{19}$ latency, the $N \overline{19} / P \overline{26}$ amplitude and the Cervical N$\overline{13}$-Cortical $\mathrm{N} \overline{19}$ interval; this latter parameter has been considered indicative of the Central Conduction Time. For the cortical SEPs recorded after the stimulation of the tibial nerve we have identified and measured the latencies and the amplitudes of the first five peaks: $\mathbf{N} \overline{34}, \mathbf{P} \overline{45}, \mathbf{N} \overline{52}, \mathbf{P} \overline{63}, \mathbf{N} \overline{79}$; we have considered specifically the $N \overline{34}$ and $P \overline{45}$ latencies, and the $N \overline{34} / P \overline{45}$ amplitudes. The conduction velocity of the sensory fibres of the median and tibial nerves was determined in a few of patients and it was always normal. The difference have been statistically evaluated by means of Student's $t$ test.

\section{Results}

Cervical SEPs from the median nerve: (table 2, figs 1-2) in the cervical SEPs (47 recordings) the N13 peak was always present, while $N \overline{9}$ and $N \overline{11}$ peaks were sometimes unclear or absent. The $N \overline{9}$ and $N \overline{11}$ latencies were slightly but insignificantly increased, while the mean value of $\mathrm{N} \overline{13}$ latency was significantly increased $(t=3.61 ; p<0.001)$; only in two cases out of 47 determinations $(4.25 \%)$ was the value clearly abnormal ( +3 SD). The $N \overline{9}-N \overline{11}$ interval was in the normal range, the $\mathrm{N} \overline{11}-\mathrm{N} \overline{13}$ interval was significantly increased $(t=3.67$; $p<$ $0.001)$; it was abnormal (+ 3 SD) in 11 deter- minations out of $42(26.2 \%)$; the $\mathrm{N} \overline{9}-\mathrm{N} \overline{13}$ interval was significantly increased $(t=2.86 ; p<0.01)$ and it was abnormal ( + 3 SD) in five determinations out of 40. This latter significant increase is likely to be due to the increase of the $\mathrm{N} \overline{11}-\mathrm{N} \overline{13}$ interval.

The central conduction time was significantly increased $(t=2.69 ; p<0.01): 11$ determinations out of $47(23.4 \%)$ showed values higher than +3 SD.

Cortical SEPs from the median nerve: (table 2 figs $1-2)$ the mean value of $\mathbf{N} \overline{19}$ latency was significantly increased $(t=2.72 ; p<0.01)$ as compared to controls: the value was abnormal $(+2.5 \mathrm{SD})$ in six determinations out of $53(11 \%)$. The amplitude measured peak to peak of $\mathrm{N} \overline{19} / \mathrm{P} \overline{26}$ was $7 \cdot 2 \mu \mathrm{V} \pm$ $4 \cdot 1$ (range $2-18 \mu \mathrm{V}$ ) in amyotrophic lateral sclerosis and $7.7 \pm 3.05 \mu \mathrm{V}$ (range $1-22 \mu \mathrm{V}$ ) in controls. This difference was not significant.

Cortical SEPs from the tibial nerve: (table 3, fig 3) $N \overline{34}$ and $P \overline{45}$ latencies were significantly increased $(t$ $=5.43$ for $\mathrm{N} \overline{34}$ and $\mathrm{t}=4.18$ for $\mathrm{P} \overline{43} ; \mathrm{p}<0.001)$ : N34 was abnormal $(+2.5 \mathrm{SD})$ in 19 determinations out of $33(57.6 \%), \mathrm{P} \overline{43}$ was abnormal $(+2.5 \mathrm{SD})$ in nine determinations out of $33(27 \cdot 3 \%)$. The N34/ $\mathbf{P} \overline{45}$ amplitude measured peak to peak was significantly reduced $(t=4.69 ; p<0.001)$ in amyotrophic lateral sclerosis patients: mean value $1.7 \pm 1.4 \mu \mathrm{V}$, range $0.5-7 \mu \mathrm{V}$; controls $3.5 \pm 1.7$ $\mu \mathrm{V}$, range $1.4-8.5 \mu \mathrm{V}$. The amplitude was altered (below the minimum value of control) in 19 determinations out of 33 (57\%).

Relations with clinical parameters: the mean latency of $\mathrm{N} 19$ was $20.0 \mathrm{~ms}( \pm 0.8), 20.10 \mathrm{~ms}( \pm 1.4), 21.7$ $\mathrm{ms}( \pm 2 \cdot 1)$ respectively in patients with duration of the disease up to 12 months (group I), from 13 to 24 months (group II) and more than 24 months (group III). There was a significant difference $(t=2 \cdot 90 ; p$ $<0.01$ ) between groups I and III on Student's $t$ test; the difference was significant also between groups II and III $(\mathrm{t}=2.95 ; \mathrm{p}<0.01)$. The $\mathrm{N} 13-\mathrm{N} 19$ interval 
Table 2 SEPs from median nerve

\begin{tabular}{|c|c|c|c|c|c|c|c|}
\hline \multirow[b]{2}{*}{ Components } & \multicolumn{4}{|c|}{ Amyotrophic läteral sclerosis } & \multicolumn{3}{|l|}{ Controls } \\
\hline & $\begin{array}{l}\text { Number of } \\
\text { Determination/cases }\end{array}$ & Mean value & $S D$ & Range & Mean value & $S D$ & Range \\
\hline $\begin{array}{l}\text { N9 latency (ms) } \\
\text { N11 latency } \\
\text { N13 latency } \\
\text { N19 latency } \\
\text { N9-N11 interval (ms) } \\
\text { N11-N13 interval } \\
\text { N9-N13 interval } \\
\text { N13-N19 interval }\end{array}$ & $\begin{array}{l}40 / 39 \\
42 / 39 \\
47 / 39 \\
53 / 45 \\
37 / 39 \\
42 / 39 \\
40 / 39 \\
47 / 39\end{array}$ & $\begin{array}{l}9 \cdot 6 \\
11 \cdot 7 \\
14 \cdot 0 \dagger \\
21 \cdot 0^{*} \\
2 \cdot 2^{\dagger} \\
2 \cdot 3^{\dagger} \\
4 \cdot 4^{*} \\
6 \cdot 2 \dagger\end{array}$ & $\begin{array}{l}0.9 \\
1 \cdot 0 \\
1 \cdot 0 \\
2.5 \\
0.4 \\
0.6 \\
0.7 \\
1 \cdot 2\end{array}$ & $\begin{array}{c}8 \cdot 1-11 \cdot 8 \\
9 \cdot 5-14 \cdot 3 \\
11 \cdot 4-16 \cdot 7 \\
18 \cdot 7-24 \cdot 7 \\
1 \cdot 5-3 \cdot 5 \\
1 \cdot 5-3 \cdot 5 \\
3 \cdot 3-5 \cdot 7 \\
5 \cdot 0-10 \cdot 2\end{array}$ & $\begin{array}{r}9 \cdot 2 \\
11 \cdot 3 \\
13 \cdot 2 \\
19 \cdot 9 \\
2 \cdot 1 \\
1 \cdot 9 \\
4 \cdot 0 \\
5 \cdot 6\end{array}$ & $\begin{array}{l}0.9 \\
0.9 \\
0.8 \\
1.2 \\
0.3 \\
0.3 \\
0.3 \\
0.4\end{array}$ & $\begin{array}{c}7 \cdot 4-10 \cdot 9 \\
9 \cdot 6-12 \cdot 5 \\
11 \cdot 6-14 \cdot 5 \\
18 \cdot 0-22 \cdot 0 \\
1 \cdot 5-2 \cdot 5 \\
1 \cdot 4-2 \cdot 6 \\
3 \cdot 1-4 \cdot 6 \\
5 \cdot 0-6 \cdot 1\end{array}$ \\
\hline
\end{tabular}

${ }^{*} p<0.01+\mathrm{p}<0.001$

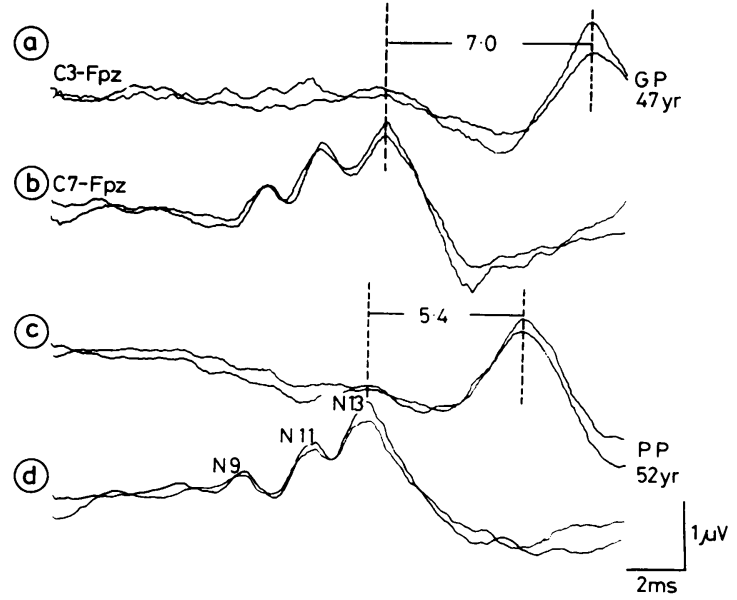

Fig. 1 Cortical $(a, c)$ and cervical $(b, d)$ SEPs from median nerve at wrist in one amyotrophic lateral sclerosis patient ( $a$ and $b$ ) and in a control case ( $c$ and $d)$; central conduction time is markedly increased in the amyotrophic lateral sclerosis patient.

increased with the duration of the disease: $5.7 \pm$ $0.46 \mathrm{~ms}$ in group I, $5.78 \pm 0.66 \mathrm{~ms}$ in group II and $6.93 \pm 1.58 \mathrm{~ms}$ in group III. There was a significant difference between groups I and III $(t=2 \cdot 35 ; p<$ $0.05)$ and between groups II and III $(t=3 \cdot 24 ; p<$ 0.001 ) at Student's $t$ test.

We observed that the N9 latency was increased in the group with spondylosis $(9.8 \mathrm{~ms} \pm 0 \cdot 8)$ as compared to the group without spondylosis $(9 \cdot 1 \mathrm{~ms} \pm$ $0.9)(\mathrm{t}=2.45 ; \mathrm{p}<0.02)$. The $\mathrm{N} \overline{11}$ latency was $12 \pm$

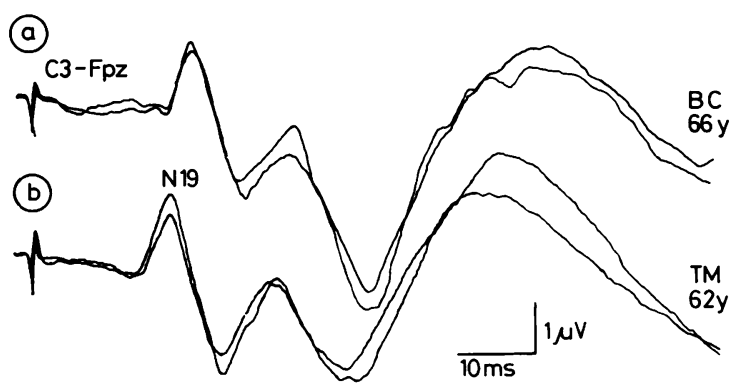

Fig. 2 Cortical SEPs from median nerve in one amyotrophic lateral sclerosis patient (a) and in a control subject (b): $N \overline{19}$ appears delayed $(3.1 \mathrm{~ms})$ in amyotrophic lateral sclerosis.

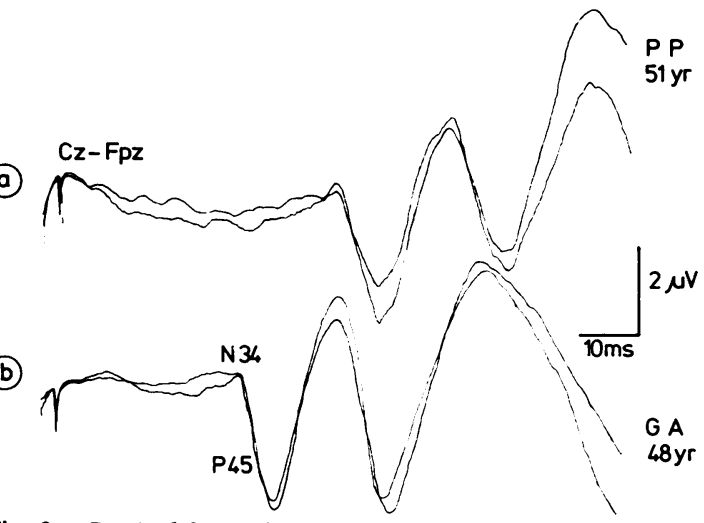

Fig. 3 Cortical SEPs from tibial nerve at ankle in one amyotrophic lateral sclerosis patient (a) and in a control subject (b): $N \overline{34}$ appears markedly delayed $(16 \mathrm{~ms})$ in amyotrophic lateral sclerosis.

Table 3 SEPs from tibial nerve

\begin{tabular}{|c|c|c|c|c|c|c|c|}
\hline \multirow[b]{2}{*}{ Components } & \multicolumn{4}{|c|}{ Amyotrophic lateral sclerosis } & \multicolumn{3}{|l|}{ Controls } \\
\hline & $\begin{array}{l}\text { Number of } \\
\text { Determination/cases }\end{array}$ & Mean value & $S D$ & Range & Mean value & $S D$ & Range \\
\hline $\begin{array}{l}\text { N34 latency (ms) } \\
\text { P45 latency } \\
\text { N34/P45 amplitude }(\mu \mathrm{V})\end{array}$ & $\begin{array}{l}33 / 30 \\
33 / 30 \\
33 / 30\end{array}$ & $\begin{array}{r}39 \cdot 6^{*} \\
48 \cdot 5^{*} \\
1 \cdot 7^{*}\end{array}$ & $\begin{array}{l}5 \cdot 2 \\
5 \cdot 9 \\
1 \cdot 4\end{array}$ & $\begin{array}{c}31 \cdot 1-48 \cdot 2 \\
41 \cdot 5-70 \cdot 0 \\
0 \cdot 5-7 \cdot 0\end{array}$ & $\begin{array}{r}34 \cdot 2 \\
45 \cdot 5 \\
3 \cdot 5\end{array}$ & $\begin{array}{l}1 \cdot 4 \\
2 \cdot 9 \\
1 \cdot 7\end{array}$ & $\begin{array}{c}31 \cdot 0-36 \cdot 5 \\
37 \cdot 2-47 \cdot 6 \\
1 \cdot 4-8 \cdot 5\end{array}$ \\
\hline
\end{tabular}

${ }^{*} \mathrm{p}<0.001$ 
$0.9 \mathrm{~ms}$ in the group with spondylosis and $11.1 \mathrm{~ms} \pm$ 0.9 in the group without spondylosis this difference being significant $(t=2.90 ; p<0.01)$.

No difference was evident between the different clinical groups. A pattern of increased latencies with increasing severity of the disease was observed, and probably depended on the increased duration of illness. The parameters obtained from the cortical SEPs derived from the tibial nerve were the same irrespective of the duration of the disease, the clinical features or the presence of cervical spondylosis.

\section{Discussion}

The measurement of cervical and cortical SEPs allows the recognition of subclinical sensory disturbances and their localisation along the afferent pathways; considerable progress has been made recently in the description and investigation of the potentials' pattern and sources ${ }^{1-16}$ and their alterations in different neurological diseases. ${ }^{17-19}$ In amyotrophic lateral sclerosis somatosensory cortical evoked potentials were investigated by Dustman ${ }^{20}$ who observed significant reduction of the peaks' amplitudes and a trend toward increased latencies. Visual evoked potentials (VEPs) were found to be normal. ${ }^{20}$ Somatosensory evoked potentials were also abnormal in $62.5 \%$ and $34 \%$ of patients with amyotrophic lateral sclerosis at lower and upper limbs respectively according to Matheson ${ }^{21}$ and in one out of three cases according to Anziska. ${ }^{22}$ A lower percentage of patients $(12 \%)$ displayed abnormal visual and brain-stem evoked potentials. ${ }^{21}$

Our results confirm that SEPs may be clearly abnormal in certain amyotrophic lateral sclerosis patients: the main abnormality is a significant delay of $\mathrm{N} \overline{13}$ and subsequent components while the amplitudes are relatively preserved. Only SEPs from the tibial nerve showed a significant decrease of amplitude. Cortical SEPs showed a generally normal

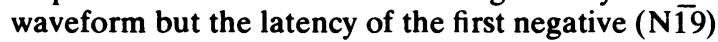
component was clearly increased. So the main pathological alteration was a slowing of conduction along the sensory pathways.

We think that the level of the sensory involvement is most probably localised within the dorsal columns and the lemniscal pathways. The presence of normal amplitude and latency of $\mathrm{N} \overline{9}$ indicates that a normal afferent volley has been conducted along the brachial plexus after the stimulation, without any delay; abnormalities of $\mathrm{N} \overline{9}$ were found only in presence of lesions of the peripheral nerves. ${ }^{19}$ Moreover the conduction velocity of the sensory fibres was in the normal range in those subjects in whom it was measured.
$\mathrm{N} \overline{11}$, which is considered to be generated near the spinal cord entry zone,,$^{13} 1519$ also displayed a normal latency. This fact, as well as the $\mathbf{N} \overline{9}-\mathrm{N} \overline{11}$ interval that was normal, seems to indicate that the roots were well preserved, at least in the subjects without cervical spondylosis; on the contrary, when spondylosis was present, the development of $\mathrm{N} \overline{11}$ potential was delayed and the $N \overline{9}-\mathrm{N} \overline{11}$ interval was increased. Growing evidence supports the notion that the $\mathrm{N} \overline{13}$ potential is generated rostrally, in the nucleus of the dorsal columns; $;^{1318} \mathrm{~N} \overline{13}$ appears constantly affected in patients with lesions of the cervical cord, caused by severe cervical myelopathy due to spondylosis. ${ }^{19}$

Hence the increased latency of $\mathrm{N} \overline{13}$ and consequently the increased $\mathrm{N} \overline{11}-\mathrm{N} \overline{13}$ and $\mathrm{N} \overline{9}-\mathrm{N} \overline{13}$ intervals suggest a slowing of conduction in the dorsal columns; on the other hand the increase of the so called central conduction time, that is, the $\mathrm{N} \overline{13}-\mathrm{N} \overline{19}$ interval, seems to indicate a delayed conduction of afferent potentials also along the lemniscal pathways up the cortex. Moreover these disturbances of the somatosensory system, clearly shown in amyotrophic lateral sclerosis, seem to progress with increasing duration and severity of the disease, as it was also indicated in the work by Dustman. ${ }^{20}$

The possibility exists that these delayed evoked responses in amyotrophic lateral sclerosis might be dependent on the pathological lesions affecting the afferent pathways, recognised in necropsy studies by Charcot and Marie ${ }^{6}$ in 1885 and Holmes, ${ }^{3}$ and more recently confirmed. ${ }^{458}$ Alternatively they might be due to a loss of the pyramidal feedback acting on the somatosensory pathways and specifically on the dorsal horns, as recently suggested ${ }^{20}$ on the basis of the well known relationships between the afferent and efferent systems.

Interestingly it has been recently shown that choline acetyltransferase activity is severely reduced in the spinal cord of patients with amyotrophic lateral sclerosis not only in the ventral horns, where it is associated with motor neurons, but also in the apical area of the dorsal horns, ${ }^{23}$ the site of the spinal interneurons: this finding gives a biochemical substrate to the morphological degeneration of Clarke's nucleus. ${ }^{4}$

The sensory system could therefore be affected by the same abnormality involving the motor neurons, but to a lesser extent and without clinical evidence. ${ }^{\prime}$

\section{References}

' Dick PJ, Stevens JC, Mulder DW, Espinosa RE. Frequency of nerve degeneration of peripheral motor and sensory neurons in amyotrophic lateral sclerosis; morphometry of deep and superficial peroneal nerves. 
Neurology (Minneap) 1975;25:781-5.

${ }^{2}$ Tohgi H, Tsukagoshi H, Toyokura Y. Quantitative changes of sural nerves in various neurological diseases. Acta Neuropath (Berl) 1977;38:95-101.

${ }^{3}$ Holmes G. The pathology of amyotrophic lateral sclerosis. G Rev Neurol Psychiatry 1909;7:693-725.

${ }^{4}$ Averback P, Crocker P. Regular involvement of Clarke's nucleus in sporadic amyotrophic lateral sclerosis. Arch Neurol 1982;39:155-6.

${ }^{5}$ Castaigne P, Cambier J, Escourolle R, Brunet P. Sclérose latérale amyotrophique et lésions dégénératives des cordons postérieurs. J Neurol Sci 1971;13:125-35.

- Charcot JM, Marie P. Deux nouveaux cas de sclérose latérale amyotrophique suivis d' autopsie. Arch Neurol (Paris) 1885; 10: 1-35, 168-186.

7 Davison C. Amyotrophic lateral sclerosis. Arch Neurol 1941;46: 1039-1056.

${ }^{8}$ Brownell B, Oppenheimer DR, Hughes JT. The central nervous system in motor neuron disease. $J$ Neurol Neurosurg Psychiatry 1970;33:338-57.

${ }^{9}$ Hirano A, Kurland LT, Sayre GP. Familial amyotrophic lateral sclerosis. Arch Neurol 1967;16:232-43.

${ }^{10}$ Drake ME. Chronic pain syndrome in amyotrophic lateral sclerosis. Arch Neurol (Chic) 1983;40:453-4.

"Cracco RQ. Spinal evoked response: peripheral nerve stimulation in man. Electroencephalogr Clin Neurophysiol 1973;35:379-86.

${ }^{12}$ Desmedt JE, Cheron G. Somatosensory evoked potentials to finger stimulation in healthy octonagerians and young adults: wave forms, scalp topography and transit times of parietal and frontal components. Electroencephalogr Clin Neurophysiol 1980;50:404-25.

${ }^{13}$ Hume AL, Cant BR. Conduction time in central somatosensory pathways in man. Electroencephalogr Clin Neurophysiol 1978;45:361-75.

14 Jones SJ. Short latency potentials recorded from the neck and scalp following median nerve stimulation in man. Electroencephalogr Clin Neurophysiol 1977; 43:853-63.

${ }^{15}$ Lesser RP, Lueders H, Hahn J, Klem G. Early somatosensory evoked potentials evoked by median nerve stimulation: intraoperative monitoring. Neurology (NY) 1981;31:1519-23.

${ }^{16}$ Lueders H, Lesser R, Hahn J, Little J, Klem G. Subcortical somatosensory evoked potentials to median nerve stimulation. Brain 1983;106:341-72.

${ }^{17}$ Bergamini L, Bergamasco B, Fra L, Gandiglio G, Mombelli AL, Mutani R. Réponses corticales et périphériques évoquées par stimulation du nerf dans la pathologie des cordons postérieurs. Rev Neurol (Paris) 1966;115:99-112.

${ }^{18}$ El Negamy E, Sedgwick EM. Delayed cervical somatosensory potential in cervical spondylosis. $J$ Neurol Neurosurg Psychiatry 1979;42:238-241.

19 Yamada T, Kimura S, Wilkinson T, Kayamori R. Short and long latency median somatosensory evoked potentials findings in patients with localized neurological lesions. Arch Neurol 1983;40:215-20.

${ }^{20}$ Dustman RE, Snyder EW, Callner DA, Beck EC. Evoked responses as a measure of cerebral dysfunction. In: Begleiter H, ed. Evoked Brain Potentials and Behavior. Plenum Press, 1979:321-63.

${ }^{21}$ Matheson JK, Harrington H, Hallet M. Abnormalities of somatosensory, visual, and brain stem evoked potentials in amyotrophic lateral sclerosis. Muscle Nerve, 1983;6:529.

${ }^{22}$ Anziska BJ, Cracco RQ. Short-latency somatosensory evoked potentials to median nerve stimulation in patients with diffuse neurologic disease. Neurology (NY) 1983;33:989-93.

${ }^{23}$ Gillberg PG, Aquilonius SM, Eckernas SA, Lundquist G, Winblad B. Choline acetyltransferase and substance P-like immunoreactivity in the human spinal cord: changes in amyotrophic lateral sclerosis. Brain Res 1982;250:394-7. 